\title{
Descriptive Analysis Regarding Use of Wechat among University Students in China
}

\author{
Xing Yu Zhu ${ }^{1} \&$ Abdul Razaque Chhachhar ${ }^{1}$ \\ ${ }^{1}$ School of Journalism and Communication, Tsinghua University, Beijing, China \\ Correspondence: Abdul Razaque Chhachhar, School of Journalism and Communication, Tsinghua University, \\ Beijing, China. E-mail: archhachhar@gmail.com
}

Received: December 7, 2015

Accepted: December 22, 2015 Online Published: January 12, 2016

doi:10.5539/ass.v12n2p151

URL: http://dx.doi.org/10.5539/ass.v12n2p151

\begin{abstract}
The main purpose this study is to explore that how the international students use Wechat in China and what kind of functions and social networking apply on Wechat. Furthermore the study indicated regarding what was most important opinion and information students adopt on Wechat. This research study is descriptive analysis about usage and Wechat as source of communication and contact with family, friends and teacher is highlighted in the paper. Total 200 international students respondents randomly were selected for data collection from Tsinghua University Beijing, China the $65.5 \%$ male and $34.5 \%$ of the female participated in the study the main findings of the study $94.5 \%$ of the respondents use Wechat to contact with friends and main purpose of use Wechat is the result showed $97.5 \%$ send message their friends and teachers. However, the $44 \%$ of the respondents agree the information that people tag and write on Wechat could be reliable. Furthermore, there many functions are available on Wechat where people can get benefit like call the taxi, transfer money recharge money in mobile phone and games but most of the respondents did not use it properly due to lack of Chinese language bearer among international students. Therefore it is possible that Wechat can introduce some new Apps where international students can get more benefit from it.
\end{abstract}

Keywords: social media, wechat, mobile media

\section{Introduction}

Social Media is the product of information revolution and growing rapidly in the last decade. It has changed the way of people's communication and information flowing. The facts that motivate people to use social media are about information, entertainment, convenience, and social interaction. (Papacharissi \& Rubin, 2000, Ko et al., 2005, Ahrama et al., 2011). Facebook and Myspace is the symbol of the power of social media and they are widely studied. At the very beginning, people use them mainly to meet friends and to seek information. (Raacke \& Bonds-Raacke, 2008) As the development of social media, it is becoming an inerasable part of modern people and its tentacles have extended beyond communication. According to Cromity (2012) the social media is mainly used in 22 aspects of people's life including business, advertising, education, news, entertainment, research, etc. It has become one of the most important tools for many professionals, decision makers, companies, and consultants, who try to target their customers, analyze the market and earn higher profit (Kaplan \& Haenlein, 2010). Social media networking is creating lot of platform for young people to communicate with each other and share their experience and take more interest to get more information about different issues of society by interacting with each other. Social networking sites allow every one to share its feelings ideas and new creativity approaches for people. Social networking enhances the capacity of students to pursue the things and sharing important things among student for more information. Webcam, video and other functions are more famous and easy to access and communicate with friends without any hindrance on social media (Awake, 2011).

Nowadays China is a rising for social media market. The rapid growth of Internet users in China is based on the massive population and the popularization of Internet. According to the $34^{\text {th }}$ Statistical Report on Internet Development in China, by the end of June 2014, China has had 632 million Internet users, with an increase of 14.42 million in the past half year (Note 1). More scholars currently turn their eyes on China. Wang (2015) starts a program called NGO2.0 to test how Chinese NGOs to use social media to increase transparency and the efficiency of sending information. He also shows a clear map of the usage of social media of Chinese NGOs. Ding (2014) also investigates on the social media practices of taxi drivers in Shenzhen. Schulte (2015) has 
studied the correlation between the information communication technology and rural education in China. Wallis' (2015) study explores the connections between micro-entrepreneurship, new media technologies, and gender in rural China. We can see that the research of social media in China already has a wide range field, but mostly are focusing on the correlation of age, place, gender, class, or organization. Not many are paying attention on the foreigners in the country while the number of foreigners in China is rising quickly. So, we think there is a need of filling this blank and this article focuses on the International students' usage of one of the most successful social media, Wechat, in China.

\section{Social Media}

Facebook, Twitter and linkden are the most popular social media in American and Europe, but they can hardly enter China because of the Internet control policy. So Chinese market breeds many local social media such as Wechat (Chinese Whatsapp), Weibo (Chinese Twitter) and Renren (Chinese Facebook). Among them, Wechat is currently in a dominated position than others. The Chinese technology tycoon, Tencent, created it in 2011. According to the report of The Statistic Portal, until the end of 2014, the active users of Wechat had reached 500 millions from 50 millions in 2011. (Note 2) Although it is a Whatsapp-like App, Wechat combines the features of Facebook, Whatsapp, entertainment, and financial system and make it more than a communication tool.

'The main objective of content communities is the sharing of media content between users. Content communities exist for a wide range of different media types, including text (e.g., BookCrossing, via which 750,000+ people from over 130 countries share books), photos (e.g., Flickr), videos (e.g., YouTube), and PowerPoint presentations (e.g., Slideshare).' (Kaplan \& Haenlein, 2010)

Wechat adopts the concept of content communities. Every user has a homepage like Facebook. They can share videos, pictures, and texts with all friends and make comments or 'like' others'. Users can download many games and play with all friends. By using Wechat, people can do online shopping, paying their bills, purchasing financial products, calling taxies and even giving red pockets through the App.

On average the popularity peak of social media is attained after 219 weeks, which is about 4 years.' (Franses, 2014) Wechat now has reached its peak and it is obviously a strong App with a huge market, but it does not get enough academic attention as it deserves. Chinese scholars currently have done most of the study on Wechat. Chen's (2013) study explores how does library system use Wechat to improve the service with lower cost, easier operation and higher customers loyalty. 'Wechat is able to send the more interesting, more pricacy information faster. So people are more willing to use the app than other social media.' (Tong, 2013) Wechat use the logic of 'Mouth to Mouth' to make users became both information sender and receiver. Because of the convenient and anonymous nature, social media users are exposed in the danger of cyber criminals of fraud, phish and prosititution and users' privacies are threatened. Gao and Zhang (2013) examined and analyzed the data of Wechat on IPhone to provide a foundation for digital forensics. Although Wechat has catched more attention, most of the study is similar to the social media studies in the west by focusing on crisis communication, customers' behavior and the influence to the society. None of them are focusing on the rising new customers, foreigners, of the software.

\section{Material and Methods}

The quantitative study approach survey using self-administered questionnaire was applied for data collection in this study. The total sample size of the data collection was 200 international students were selected from Tsinghua University Beijing China while the simple random sampling was used for data collection in this study. The main objective of the study was to know that how the international students use Wechat and what kind of application and function they use on their mobile phones. The data was analyzed by using SPSS software version 21.

\section{Result and Discussion}

There are 200 respondents participated in this research. Because the surveys were handed out in Tsinghua University, most of the participants are students ( $\mathrm{n}=183$ students, $\mathrm{n}=17$ other careers) and young generation. There were $62 \%$ of the respondents aging was from 20 to 25 while the $25.5 \%$ of the respondents age were from 26 to 30 , while $10.5 \%$ of the respondents age were from 31 to 40 and only $2 \%$ of the respondents age was above 40 with the mean value of 1.52 .673 . However, $33.5 \%$ of the respondents education level were bachelor degree, $44 \%$ of the respondents were master degree, while $11 \%$ of the respondents were with a $\mathrm{PhD}$ degree and $11.5 \%$ were under bachelor. The mean level was (2.00.Std 0.95). However, the respondents were also asked about their family number of members the result indicated that $45.3 \%$ have less than 3 family members (immediate family), $17 \%$ have 3 family members, $12.5 \%$ have 4 family members and $25 \%$ have more than 4 family members while 
the mean was 2.91 Std 1.03) moreover the $29 \%$ of the respondents participants in this study were Christian, $11.5 \%$ of the respondents were Muslim, $1.5 \%$ were Judaism, $47.5 \%$ have no religion and $10.5 \%$ are others.

Table 1. Demographic profile

\begin{tabular}{|c|c|c|c|c|}
\hline Variable & Frequency & Percent & Mean & Std. Deviation \\
\hline \multicolumn{5}{|l|}{ Age } \\
\hline $20-25$ & 124 & 62.0 & \multirow[t]{3}{*}{1.52} & \multirow{4}{*}{.763} \\
\hline $26-30$ & 51 & 25.5 & & \\
\hline $31-40$ & 21 & 10.5 & & \\
\hline Above 40 & 4 & 2.0 & & \\
\hline \multicolumn{3}{|l|}{ Gender } & \multirow{3}{*}{1.35} & \multirow{3}{*}{.476} \\
\hline Male & 131 & 65.5 & & \\
\hline Female & 69 & 34.5 & & \\
\hline Career & & & \multirow{3}{*}{1.08} & \multirow{3}{*}{.279} \\
\hline Student & 183 & 91 & & \\
\hline Others & 17 & 8.5 & & \\
\hline \multicolumn{5}{|l|}{ Education } \\
\hline Bachelor & 67 & 33.5 & \multirow{4}{*}{2.00} & \multirow{4}{*}{.953} \\
\hline Master & 88 & 44.0 & & \\
\hline $\mathrm{PhD}$ & 22 & 11.0 & & \\
\hline Under Bachelor & 23 & 11.5 & & \\
\hline \multicolumn{5}{|c|}{ Monthly Income (USD) } \\
\hline Lower than 500 & 117 & 58.5 & \multirow{3}{*}{1.66} & \multirow{3}{*}{.852} \\
\hline 600-1000 & 33 & 16.5 & & \\
\hline Over 1000 & 50 & 25 & & \\
\hline \multicolumn{5}{|c|}{ Number of Family Members } \\
\hline Less than 3 & 27 & 45.3 & \multirow{4}{*}{2.91} & \multirow{4}{*}{1.03} \\
\hline 3 Members & 35 & 17 & & \\
\hline 4 Members & 67 & 12.5 & & \\
\hline More than 4 & 71 & 25 & & \\
\hline \multicolumn{5}{|l|}{ Religion } \\
\hline Christian & 58 & 29 & \multirow{5}{*}{2.99} & \multirow{5}{*}{1.47} \\
\hline Muslim & 23 & 11.5 & & \\
\hline Judaism & 3 & 1.5 & & \\
\hline None & 95 & 47.5 & & \\
\hline Others & 21 & 10.5 & & \\
\hline
\end{tabular}

\section{Use of Wechat}

Table 2 result indicated regarding the usage and stay of the respondents in China where result showed that $45.5 \%$ of the respondents are staying in China less than one year, while $17 \%$ of respondents are living last one year $12.5 \%$ of the respondents are living last tow years in China.However, $25 \%$ of the respondents are living last three years here it shows that the students who are living last three years most of them are Master students. The respondents were also asked about how long they are using Wechat where the result indicated that $67 \%$ of the respondents are using Wechat less than one year while 7\% of the respondents one year $8.5 \%$ two years and $15 \%$ last three years are using Wechat. Furthermore, respondents were also asked about why they are using Wechat where result 
showed that $94.5 \%$ of the respondents use Wechat to chat with their friends, which is very easy to contact with friends without any disturbance. Wechat, is more easy access to communicate with friends. While $20 \%$ of the respondents use Webcam with their family mostly respondents use webcam video chat with their family. Similarly $20 \%$ of the respondents seek information by of their friends by using Wechat and only $10 \%$ of the respondents use gets other information. The respondents were also inquired about how long time they use Wechat every day where result indicated that $39.5 \%$ of the respondents use Wechat every day less than one hour in a day $32.5 \%$ of the respondents use one to two hours in a day. However, it was showed that $28 \%$ of the respondents use Wechat more than three hour every day. The respondents were also asked about most function use of on Wechat $97.5 \%$ of the respondents were using sending the message to family, friends and teachers on the Wechat is the famous source of communication with each others in university students. The second function of the Wechat is moments where respondents use this function frequently where result revealed that $22.5 \%$ of the respondents use moments and tag their activities and only $6 \%$ of the respondents use their financial banking system on Wechat while it was showed that no any one respondent were playing any game on Wechat

Table 2. Use of Wechat among international students

\begin{tabular}{lcc}
\hline \multicolumn{1}{c}{ Variables } & Frequency & Percentage \\
\hline How long have you been in China? & 91 & \\
Less than one year & 34 & 45.5 \\
One year & 25 & 17.0 \\
Two years & 50 & 2.5 \\
More than three years & & 25.0 \\
From how many months or years you are using Wechat? & 134 & 67.0 \\
Less than one year & 14 & 7.0 \\
One year & 17 & 8.5 \\
Two years & 5 & 2.5 \\
Three years & 30 & 15. \\
More than three years & & \\
Why do you use Wechat? & 189 & 94.5 \\
Chat with friends & 40 & 20.0 \\
Webcam with family & 40 & 20.0 \\
Seeking information & 20 & 10.0 \\
Others & & \\
How long you use Wechat every day? & 79 & 39.5 \\
Less than 1 hour & 65 & 32.5 \\
One to two hours & 56 & 28.0 \\
More than two hours & & \\
Which function do you use the most in Wechat? & 195 & 97.5 \\
Sending message & 45 & 22.5 \\
Moments & 23 & \\
Webcam & 0 & \\
Games & 12 & \\
Financial services and banking & & \\
\hline & & \\
\hline
\end{tabular}

\section{Usage and Importance of Wechat}

Data from table 3 shows the information regarding the usage and importance of Wechat. Among all the participants, $13.5 \%$ of the respondents were strongly agree and $28 \%$ agree regarding Wechat as a good tool as 
compare traditional media while $32.5 \%$ of the respondents were neutral about the good tool of Wechat and $17 \%$ were disagree and $9 \%$ were strongly disagree that Wechat is not good tool to get the information. However, respondents were asked about their own activities on moment the result revealed that $29.5 \%$ of the respondents were agree that they keep their own activities on moments while $36.5 \%$ did not understand that they only keep their moments on Wechat while $25.5 \%$ were disagree and $8.5 \%$ of the respondents were strongly disagree about it. Furthermore, the respondents were asked about the authenticity of the Wechat information where result indicated that $30 \%$ of the respondents were agree and $43 \%$ of the respondents were neutral about get the authenticity of Wechat information and only $4 \%$ were strongly disagree about the authenticity information on Wechat it was showed that many students give and send information in different groups and tag on moments therefore students did not confirm its authenticity on Wechat. The respondents were used to asked about read the comments on Wechat the result showed that $31 \%$ were strongly agree that they read different comments which write their friends on Wechat. The respondents were also inquired about their comments on different information where result indicated that $18.5 \%$ of the respondents agree and asked that they give comments on different information such as on news research papers and also on poetry while $36.5 \%$ of the respondents were disagree and said that they do not give comments without any much information regarding the subject while some of them were agree that they avoid to give comments on some sensitive issues of the society on Wechat while $25 \%$ of the respondents were neutral about to give comments on each published information on Wechat.

The respondents were asked about the comments of others on Wechat his own opinion where result showed that $33.5 \%$ of the respondents strongly agree that they change their own opinion to see others comments on different social and political issues while $25 \%$ were neutral and they disagree and understand that it is not necessary that they should change their own opinion on different comments on Wechat while $17 \%$ of the respondents were strongly disagree and said that it is not important that $u$ depend on others and change your own statement. The respondents were asked about rely on the information the result showed that $44 \%$ of the respondents were strongly agree and said they believe that the information which tag on Wechat is reliable while $15.5 \%$ of the respondents were disagree and said that they cannot rely on everyone post on Wechat. However, the respondents were asked about the freedom of speech on Wechat where result revealed that $31 \%$ of the respondents were agree about the Wechat best place share its speech without any hesitation and $31.5 \%$ of the respondents were neutral about this statement and they are not either agree not disagree about the freedom of speech while $14.5 \%$ of the respondents were disagree about the freedom of speech and understand that Wechat is not suitable for the freedom of speech. The study further showed that $16.5 \%$ of the respondents were agree that the majority intend view in the Wechat of events while $44 \%$ of the respondents were neutral and understand that it not necessary to intend the majority of the events on Wechat while $18 \%$ of the respondents were disagree about the intend event on Wechat. The respondents results showed about the reliable information regarding celebrities indicated that $49 \%$ of the respondents were neutral and understand that they have not sure either it is right information or wrong information about the celebrities of media industries. Furthermore, $11 \%$ of the respondents were agree and understand the information can be true which post on Wechat by different people and users of Wechat. However, the respondents were also asked about the large number of comments people give on different issues and news so what is their statement regarding it either on the more comments can person rely on information where result indicated that $47 \%$ of the respondents disagree on it and said it is not very important that large number comments can motivated them to agree on it where further $17.5 \%$ of the respondents were agree and understand that large numbers comments on different things can be reliable the information (Refer Table 3 ).

Table 3. Information and opinion on Wechat

\begin{tabular}{lccccc}
\hline \multicolumn{1}{c}{ Statement } & SA & A & N & DA & SD \\
\hline $\begin{array}{l}\text { I understand Wechat is a good tool for hotspot } \\
\text { affairs. I compared with the traditional media, I }\end{array}$ & 27 & 56 & 65 & 34 & 18 \\
prefer to use Wechat to understand current events & $(13.5 \%)$ & $(28 \%)$ & $(32.5 \%)$ & $(17 \%)$ & $(9 \%)$ \\
$\begin{array}{l}\text { I would use Wechat to publish my activities on } \\
\text { moments and often use to forward information }\end{array}$ & 20 & 39 & 73 & 51 & 17 \\
$\begin{array}{l}\text { I will first confirm the authenticity of the Wechat in } \\
\text { the information }\end{array}$ & $(10 \%)$ & $(21.5 \%)$ & $(36.5 \%)$ & $(25.5 \%)$ & $(8.5 \%)$ \\
I often use to read comments on Wechat & $(10.5 \%)$ & $(30 \%)$ & $(43 \%)$ & $(12.5 \%)$ & $(4 \%)$ \\
\hline
\end{tabular}




\begin{tabular}{lccccc}
\hline \multicolumn{1}{c}{ Statement } & $\mathrm{SA}$ & $\mathrm{A}$ & $\mathrm{N}$ & $\mathrm{DA}$ & $\mathrm{SD}$ \\
\hline & $(31)$ & $(16 \%)$ & $(7 \%)$ & $(28 \%)$ & $(18 \%)$ \\
I prefer to give comment on different information & 37 & 32 & 50 & 73 & 8 \\
& $(18.5 \%)$ & $(16 \%)$ & $(25 \%)$ & $(36.5 \%)$ & $(4 \%)$ \\
On Wechat others comment on the different issues & 67 & 31 & 18 & 50 & 34 \\
change my opinion & $(33.5 \%)$ & $(15.5 \%)$ & $(9 \%)$ & $(25 \%)$ & $(17 \%)$ \\
Do you rely the information post on wechat & 89 & 46 & 24 & 31 & 10 \\
& $(44 \%)$ & $(23 \%)$ & $(12 \%)$ & $(15.5 \%)$ & $(5 \%)$ \\
Wechat is freedom of speech where you can write & 34 & 62 & 63 & 29 & 12 \\
your opinion & $(17 \%)$ & $(31 \%)$ & $(31.5 \%)$ & $(14.5 \%)$ & $(6 \%)$ \\
I tend to agree with the majority view in the Wechat & 21 & 33 & 88 & 36 & 22 \\
of events & $(10.5 \%)$ & $(16.5 \%)$ & $(44 \%)$ & $(18 \%)$ & $(11 \%)$ \\
I also agree with the majority view in the Wechat of & 15 & 32 & 99 & 40 & 14 \\
events & $(7.5 \%)$ & $(16 \%)$ & $(49.5 \%)$ & $(20 \%)$ & $(7 \%)$ \\
Is the information published about celebrity reliable & 17 & 22 & 98 & 38 & 25 \\
& $(8.5 \%)$ & $(11 \%)$ & $(49 \%)$ & $(19 \%)$ & $(12.5 \%)$ \\
$\begin{array}{l}\text { Comments in large numbers information can be } \\
\text { reliable }\end{array}$ & 14 & 35 & 38 & 94 & 19 \\
Wechat in everyone's opinion are somewhat positive & $(7 \%)$ & $(17.5 \%)$ & $(19 \%)$ & $(47 \%)$ & $(9.5 \%)$ \\
rational & $(11 \%)$ & $(23.5 \%)$ & $(43.5 \%)$ & $(17 \%)$ & $(5 \%)$ \\
I think the prospects for the use of Wechat to & 25 & 69 & 73 & 23 & 10 \\
participate in interactive hotspots considerable & $(12.5 \%)$ & $(34.5 \%)$ & $(36.5 \%)$ & $(11.5 \%)$ & $(5 \%)$ \\
\hline
\end{tabular}

\section{Conclusion}

Although the study showed that most of the respondents use Wechat for sending a messages to friends and chat with each other, there are many other functions are available on Wchat where students can get more benefit from it. The biggest obstacle preventing foreigners using different function of Wechat is security issue and user habit. For example, the official public account, which is a cooperation and promotion service launched for famous persons, government, media and enterprises, requires registration of Chinese ID card in order to supervised by the Chinese government. Foreigners cannot get access by using passport. The function 'Moments', a personal homepage and sharing system like Facebook and Twitter is also extremely popular among Chinese people, but only $22.5 \%$ of the participants are using the system. Most of the foreigner students are used to use western social media like Facebook and Twitter, it is hard to change their behavior especially all their friends back to their hometown are using Facebook. According to the study, the incompletion of using Wechat affects their opinion about the APP directly. In table 3, we can see a lot of people hold a neutral position on the questions about the information flowing and reliability in Wechat. Many participants never pay attention on news or information other than just chatting with friend on Wechat, so they do not have a clear idea about the informational ecosystem on Wechat. The study also indicates that some students have no proper information regarding use of Wechat and proper use of different functions. However, Wechat is not commonly use around the world like other social media but it can be expected that this will also be famous soon around the globe.

\section{References}

Ahrama, T., Karwowskia, W., \& Amabab, B., (2011). Collabo- rative systems engineering and social-networking approach to design and modeling of smarter products. Behaviour \& Information Technology, 30(1), 13-26.

Awake. (2011, July). What Should I know social networking? (Part 1, pp. 24-25).

Chen, Y. (2013). Wei Xin Gong Gong Ping Tai Ji Qi Tu Shu Guan Yi Dong Fu Wu Zhong De Ying Yong Ji Yan Jiu (The Use and Study of Wechat in Library Mobile Service). Research on Library Science, 20, 71-74. 
Cromity, J. (2012). The impact of social media in review. New Review of Information Networking, 17(1), 22-33

Ding, W. (2014). Liu dong de jia yuan (Mobile homelands). Beijing: Social Science Academic Press.

Franses, P. H. (2014). The life cycle of social media. Applied Economics Letters. http://dx.doi.org/10.1080/ 13504851.2014.978069

Gao, F., \& Zhang, Y. (November, 2013). Analysis of Wechat on IPhone. Atlantis Press.

Kaplan, A. M., \& Haenlein, M. (2010). Users of the world, unite! The challenges and opportunities of Social Media. Business Horizons, 53, 59-68.

Ko, H., Cho, C., \& Roberts, M. S. (2005). Internet uses and gratifications. Journal of Advertising, 34(2), 57-70.

Papacharissi, Z., \& Rubin, A. M. (2000). Predictors of Internet use. Journal of Broadcasting and Electronic Media, 44(2), 175-196.

Raacke, J., \& Bonds-Raacke, J. (2008). MySpace and Facebook: Applying the uses and gratifications theory to exploring friend-networking sites. Cyber Psychology \& Behavior, 11(2), 169-174.

Schulte, B., (2015). (Dis) Empowering technologies: ICT for education (ICT4E) in China, past and present. Chinese Journal of Communication, 8(1), 59-77.

Tong, H. (2013). Research on Wechat according to communication study and its influence. Research On Journalism Publication And Mass Communication, 9, 61-66.

Wallis, C. (2015). Micro-entrepreneurship, new media technologies, and the reproduction and reconfiguration of gender in rural China. Chinese Journal of Communication, 8(1), 42-58.

Wang, J. (2015). NGO2.0 and social media praxis: activist as researcher. Chinese Journal of Communication, $8(1), 18-41$.

\section{Notes}

Note 1. The report is done by China Internet Network Information Center. Retrieved from http://www1.cnnic.cn/ IDR/ReportDownloads/201411/P020141102574314897888.pdf

Note 2. Number of monthly active WeChat users from 2nd quarter 2010 to 4th quarter 2014 (in millions). Retrieved from http://www.statista.com/statistics/255778/number-of-active-wechat-messenger-accounts/

\section{Copyrights}

Copyright for this article is retained by the author(s), with first publication rights granted to the journal.

This is an open-access article distributed under the terms and conditions of the Creative Commons Attribution license (http://creativecommons.org/licenses/by/3.0/). 